\title{
Sustainability of apple fruits cv. Berkutovskoye to physiological diseases under different storage technologies
}

\author{
Vladimir Gudkovsky, Lyudmila Kozhina*, Yuri Nazarov, and Alena Sutormina \\ Federal State Budgetary Scientific Institution "Federal Research Center named after I.V. Michurin", \\ 393773 Michurinsk, Tambov region, Russian Federation
}

\begin{abstract}
The research was carried out at the Federal Research Center named after I.V. Michurin (Tambov region, Russia), using a promising apple cultivar Berkutovskoye with a high susceptibility to superficial scald. The aim of the research was to study the influence of storage technologies with different oxygen content in the storage atmosphere on the losses from scald and other diseases of apple fruit cv. Berkutovskoye. Control and 1MCP-treated fruits were stored under regular (RA) and controlled atmosphere with its modifications (ULO-1: O2 - 1.2-1.5\%, $\mathrm{CO} 2-1.2-$ $1.5 \%$, ULO-2: $\mathrm{O} 2-0.8 \%, \mathrm{CO} 2-0.8-1 \%$, DCA - $\mathrm{O} 2-0.7 \%$ with a decrease to $0.4 \%, \mathrm{CO} 20.7-0.8 \%$ ). Protection from scald was not provided in control fruits stored under RA, ULO-1, ULO-2 and DCA conditions, the appearance of the disease occured earlier under ULO-1 conditions with higher degree of its development. 1-MCP treatment inhibits the synthesis of ethylene, $\alpha$-farnesene, and CT281. The technology 1-MCP + RA provides fruit protection from scald for 3-4 months, with a decrease in fruit quality and the appearance of greasiness (up to 10\%); the technology 1MCP + ULO-1 protects fruits from scald for no more than 3-4 months; technologies 1-MCP + ULO-2 and 1-MCP + DCA - for more than 4.5 months. Reducing the time of atmosphere setup and optimization of storage parameters for ULO-2 and DCA technologies (with an oxygen content less than $0.8 \%$ ) can provide a higher level of the quality maintenance of apple fruits cv. Berkutovskoye, without risks of anaerobic disorders.
\end{abstract}

\section{Introduction}

Berkutovskoye is an apple cultivar created by O.D. Berkut and G.V. Kondratyeva (specialists of Saratov experimental horticulture station, Russia) by crossing the cultivars Cortland, Antonovka obyknovennaya and Anis rosovo-polosaty. The cultivar is adapted to the conditions of Central regions of Russia, and the fruits can compete with fruits of many foreign cultivars due to their good flavor. Berkutovskoye is one of the few apple cultivars of domestic selection that can be presented in distributing facilities under its own name, and not as a "seasonal apple". However, low production volumes and the lack of effective

\footnotetext{
* Corresponding author: kozhina@fnc-mich.ru
} 
storage technologies make systematic fruit deliveries impossible within 10-12 months and, therefore, restrict the cultivar promotion.

The fruits cv. Berkutovskoye are characterized by intensive coloration, crispy flesh consistency and a very high susceptibility to scald, which is probably inherited from two susceptible cultivars - Antonovka obyknovennaya and Cortland.

Superficial scald is one of the main physiological diseases of apple fruits. The damage from the disease can be significant for the enterprise economy.

It is known that all postharvest activities (chemical treatments, including 1-MCP, low storage temperatures, changed content of $\mathrm{O}_{2}$ and $\mathrm{CO}_{2}$ in storage atmosphere, etc.) have a stressful effect on the fruit state. The oxidative stress may occur when the production of reactive oxygen species (ROS) exceeds the antioxidant potential. The accumulation of ROS leads to injuring or death of fruit cells and the development of physiological diseases [1], including scald induced by low storage temperatures [2].

The oxidation of $\alpha$-farnesene (a low-volatile compound in the fruit cuticle) into conjugated trienes $\left(\mathrm{CT}_{281}\right)$ and ketone 6-methyl-5-hepten-2-one ( $\mathrm{MHO}$ ), which are considered as the main causal agents of superficial scald [2-5], is a well-known and confirmed scientific hypothesis about the mechanisms of scald development.

Since the late 1950s, the antioxidant diphenylamine (DPA) has been the primary method of scald control worldwide. In 2009, the European Commission for Food Safety limited its use.

Currently, treatment with the ethylene biosynthesis inhibitor 1-MCP is used commercially to control scald development. This compound blocks ethylene binding sites and thereby reduces the accumulation and further oxidation of $\alpha$-farnesene [6-8]. Nevertheless, despite the high efficiency of 1-MCP-treatment, the absence or insufficient development of flavor and aroma specific for cultivar, caused by inhibition of fruit ripening, as well as an additional "chemical load" on the fruits initiate the search for new ways to preserve product quality.

In recent years, storage technologies with a low $\mathrm{O}_{2}$ content have been developed and industrialized as alternatives to the use of the synthetic antioxidant DPA [9-11] and, possibly, 1-MCP, to reduce losses from scald and maintain the quality of apple fruits.

Data have been obtained proving that lowered $\mathrm{O}_{2}$ level under storage in controlled atmosphere reduces losses from scald, moreover, ULO storage $\left(\mathrm{O}_{2}<1.5 \%\right)$ is the most effective [3], while DCA storage conditions $\left(\mathrm{O}_{2}<0.8 \%\right.$ at $\left.\mathrm{CO}_{2}<1 \%\right)$ ensure protection from scald for some apple cultivars grown in Europe and the USA [10-12] without anaerobic disorders and alcohol off-flavor. Researching the influence of storage technologies with a low oxygen content on scald development and other diseases of fruits of apple cultivars zoned in the Central Black EarthRegion of Russia (Berkutovskoye) has not been carried out yet.

The aim of the research was to study the influence of storage technologies with different oxygen content in the storage atmosphere on the losses from scald and other diseases of fruits cv. Berkutovskoye.

\section{Materials and methods}

The experiments were carried out at the Federal Scientific Center named after I.V. Michurin (Tambov region, Russia) in 2020-2121, using a promising apple cultivar Berkutovskoye with a high susceptibility to superficial scald.

The fruits were harvested when internal ethylene concentration was 0.1-1.0 ppm, content of $\alpha$-farnesene $-31.98 \mathrm{nmol} / \mathrm{cm}^{2}$, content of $\mathrm{CT}_{281}-1.16 \mathrm{nmol} / \mathrm{cm}^{2}$. 
The ethylene content in storage atmosphere and in fruit tissues (ppm) was determined using gas chromatograph GC-2014 (SHIMADZU, Japan), equipped with a flame ionization detector [13].

The content of $\alpha$-farnesene and its oxidation products $\left(\mathrm{CT}_{281}\right)$ in storage atmosphere and in the cuticle of fruit skin $\left(\mathrm{nmol} / \mathrm{cm}^{2}\right)$ was determined in indicator tapes and in fresh-cut skin stripes from the shadowed side of the fruit, respectively. The absorption spectra of hexane extracts were recorded using a spectrophotometer (UV-1800, SHIMADZU, Japan) $[14,15]$.

Flesh firmness $\left(\mathrm{kg} / \mathrm{cm}^{2}\right)$ was measured with an 11-mm tip of the penetrometer (FT-327).

Treatment with 1-MCP (ethylene biosynthesis inhibitor Fitomag ${ }^{\circledR}$, Russia) was applied on the half of the total experiment fruit on the harvest day. Treatment time $-24 \mathrm{~h}$.

Losses from scald and other diseases were evaluated visually after 2 and 4.5 months of storage plus 7 days of shelf life at $\mathrm{T}=+20^{\circ} \mathrm{C}$ (imitation of sales period), and results were expressed as percentages of the total number of fruit.

The experiment was composed of following storage conditions:

1. Control fruits (without $1-\mathrm{MCP}$ treatment) stored in a regular air, $\mathrm{RA}\left(\mathrm{T}=+1{ }^{\circ} \mathrm{C}, \mathrm{CO}_{2}\right.$ $\left.=0.03 \%, \mathrm{O}_{2}=21 \%\right)-\mathbf{C}+\mathbf{R A}$;

2. 1-MCP-treated fruits stored in a regular air, RA $\left(\mathrm{T}=+1{ }^{\circ} \mathrm{C}, \mathrm{CO}_{2}=0.03 \%, \mathrm{O}_{2}=21 \%\right)$ - T + RA;

3. Control fruits stored under ultra-low oxygen content, ULO-1 $\left(\mathrm{T}=+1{ }^{\circ} \mathrm{C}, \mathrm{O}_{2}=1.5\right.$ $2.0 \%, \mathrm{CO}_{2}=1.2-1.5 \%$ ) - C + ULO-1;

4. 1-MCP-treated fruits stored under ultra-low oxygen content, ULO-1 $\left(\mathrm{T}=+1{ }^{\circ} \mathrm{C}, \mathrm{O}_{2}=\right.$ $\left.1.5-2.0 \%, \mathrm{CO}_{2}=1.2-1.5 \%\right)$ - T + ULO-1;

5. Control fruits stored under ultra-low oxygen content, ULO-2 $\left(\mathrm{T}=+1{ }^{\circ} \mathrm{C}, \mathrm{O}_{2}=0.8\right.$ $\left.0.9 \%, \mathrm{CO}_{2}=0.8-0.9 \%\right)-\mathbf{C}+\mathbf{U L O}-2$;

6. 1-MCP-treated fruits stored under ultra-low oxygen content, ULO-2 $\left(\mathrm{T}=+1{ }^{\circ} \mathrm{C}, \mathrm{O}_{2}=\right.$ $\left.0.8-0.9 \%, \mathrm{CO}_{2}=0.8-0.9 \%\right)-\mathbf{T}+\mathbf{U L O}-2$;

7. Control fruits stored in a dynamic controlled atmosphere, DCA $\left(\mathrm{T}=+1{ }^{\circ} \mathrm{C}, \mathrm{O}_{2}=0.8\right.$ $0.9 \%$, with a decrease to $0.4 \%, \mathrm{CO}_{2}=0.8-0.9 \%$ ) - C + DCA;

8. 1-MCP-treated fruits stored in a dynamic controlled atmosphere, DCA $\left(\mathrm{T}=+1{ }^{\circ} \mathrm{C}, \mathrm{O}_{2}\right.$ $=0.8-0.9 \%$, with a decrease to $\left.0.4 \%, \mathrm{CO}_{2}=0.8-0.9 \%\right)-\mathbf{T}+\mathbf{D C A}$.

To ensure RA conditions, cold storage rooms with a capacity of 5 tons were used.Industrial storage rooms of 150 tons capacity were used for ULO-1 storage. Storage conditions $\left(\mathrm{O}_{2}=1.2-1.5 \%, \mathrm{CO}_{2}=1.2-1.5 \%\right)$ were established by a nitrogen generator and a $\mathrm{CO}_{2}$-scrubber.

Storage conditions of ULO-2 and DCA were ensured by laboratory complex created by the Federal Scientific Center named after I.V. Michurin together with PLAWI "Plattenhardt + Wirth GmbH" (Germany) and its subsidiary company "PLAVI-Service" (Russia) with experimental chambers $\left(0.9 \mathrm{~m}^{3}\right)$ with the possibility of autonomous setup and maintenance of storage regimes. Chlorophyll fluorescence sensors were used for DCA establishing (DCA-CF). High-tech equipment, high-precision sensors and modern software were used to setup, maintain and control storage parameters such as temperature, air humidity, $\mathrm{CO}_{2}$ and $\mathrm{O}_{2}$ content.

The recommended temperature and oxygen regime was obtained for 6 and 11 days, respectively. The lowest oxygen limit (LOL) under DCA-CF conditions was reached on the 28 th and 70 th day of storage with $\mathrm{O}_{2}$ content $0.4 \%$, then it was maintained at $0.2-0.3 \%$ higher than LOL.

There were 4 boxes with 10-11 kg of fruits for each storage option.

The data were submitted to statistic analysis using Microsoft Excel computer program. 


\section{Results and discussion}

\subsection{Flesh firmness}

The lowest flesh firmness after 2 and 4.5 month of storage and shelf life was observed in fruits stored under regular air conditions $(\mathrm{C}+\mathrm{RA}$ ) (figure 1).

Storage conditions with an oxygen content less than $0.8 \%$ in C-ULO-2 and C-DCA ensured a higher firmness retention compared with C-ULO-1, but there was no significant difference between C-ULO-2 and C-DCA.

The 1-MCP treatment provided a higher flesh firmness maintenance under all studied storage conditions, with the highest flesh firmness of fruits stored under T-ULO-2 and TDCA.

\subsection{Internal ethylene concentration.}

Control fruits stored under RA conditions (C-RA) reached the highest internal ethylene content after 4.5 months of storage - 727.2 ppm (after shelf life - $846.1 \mathrm{ppm}$ ). Storage conditions of controlled atmosphere restrained ethylene accumulation with the highest efficiancy in C-ULO-2 and C-DCA with a lower oxygen content (figure 1).

The 1-MCP treatment provides effective inhibition of ethylene accumulation under all storage technologies. An equivalently low level of the hormone (4-6 ppm) was noted during the first 2 months of storage, a low level remained in fruits under T-ULO-2 and T-DCA after 4.5 months of storage and even after shelf life period. In T-OA and T-ULO-1 the efficiency of 1-MCP treatment decreased with an increase of storage duration (after 2 months).

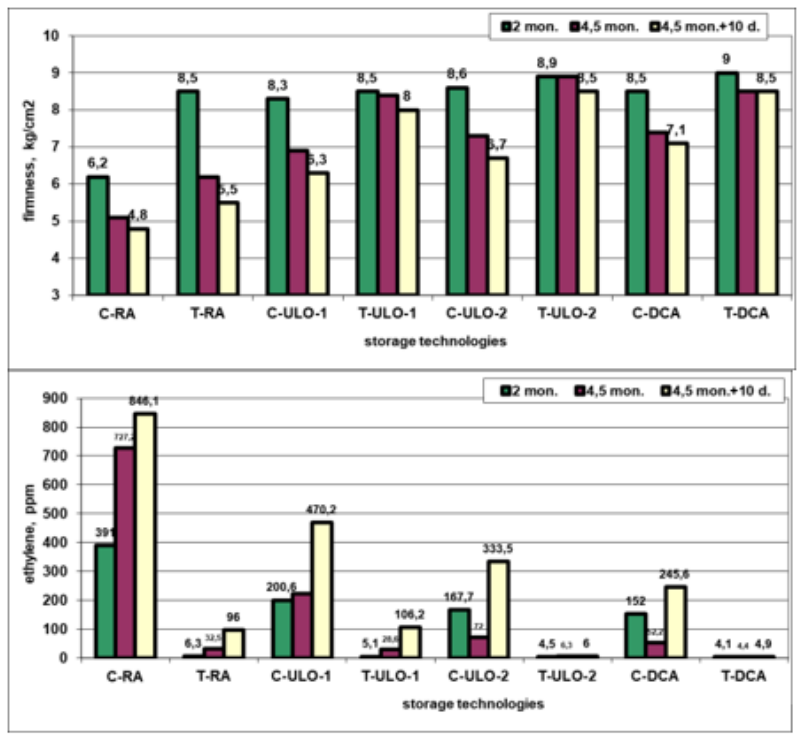

Fig. 1. Effects of storage technologies and storage duration on flesh firmness and internal ethylene concentration in fruits cv. Berkutovskoye. Data of 2020-2021. 


\subsection{Content of $\alpha$-farnesene}

The fruits cv. Berkutovskoye are characterized by a very high susceptibility to scald, which is confirmed by the data on $\alpha$-farnesene accumulation at harvest $-31.98 \mathrm{nmol} / \mathrm{cm}^{2}$. Active synthesis of this unsaturated hydrocarbon was noted in control fruits cv. Berkutovskoye during the first 2 months of storage $\left(130-170 \mathrm{nmol} / \mathrm{cm}^{2}\right.$ ) (figure 2). It is possible that the observed content is not the maximum value, because some amount of the hydrocarbon has already oxidized, that is evidenced by the accumulation of $\alpha$-farnesene oxidation products $\mathrm{CT}_{281}$. A decrease in the $\alpha$-farnesene content in the cuticle of fruit skin was noted under all storage technologies after 4.5 months of storage $\left(50-80 \mathrm{nmol} / \mathrm{cm}^{2}\right)$, while there was an intensification of its synthesis during shelf life $\left(100-120 \mathrm{nmol} / \mathrm{cm}^{2}\right)$. The exception were fruits under C-ULO-1, where an active decrease in the $\alpha$-farnesene content was accompanied by the accumulation of its oxidation products $\left(\mathrm{CT}_{281}\right)$ and by the intensive scald development.

The 1-MCP treatment decreased $\alpha$-farnesene accumulation under all storage technologies by 2-3 times compared with control fruits. However, a high level of $\alpha$ farnesene content after 2 months of storage $\left(48-75 \mathrm{nmol} / \mathrm{cm}^{2}\right)$ and tendencies of its accumulation (most evident in fruits stored under T-RA and T-ULO-1) indicate the risks of scald development in MCP-treated fruits.

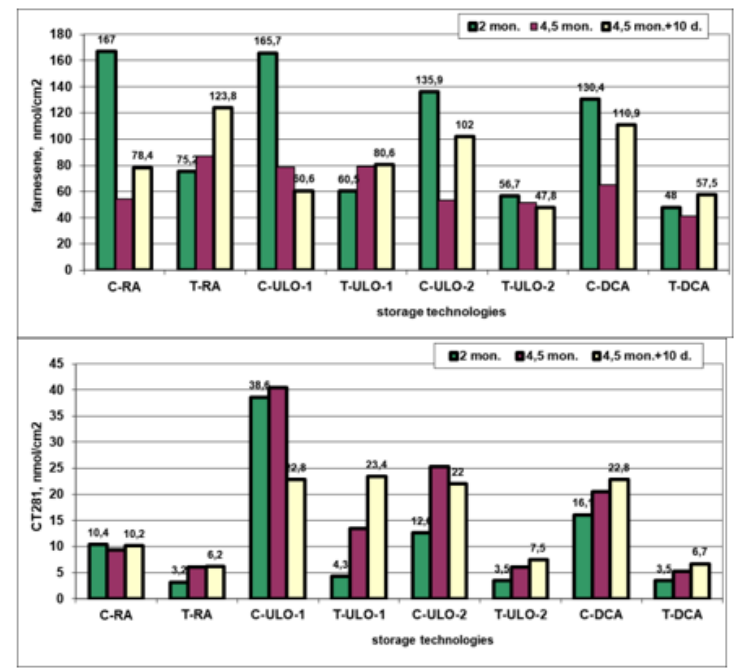

Fig. 2. Effects of storage technologies and storage duration on $\alpha$-farnesene and CT281 content in fruits cv. Berkutovskoye. Data of 2020-2021.

$C T_{281}$. After 2 months of storage, the content of $\mathrm{CT}_{281}$ in all control fruits exceeded 10 $\mathrm{nmol} / \mathrm{cm}^{2}$ (figure 2), which indicated the risks of scald development. The highest $\mathrm{CT}_{281}$ level $\left(38.6 \mathrm{nmol} / \mathrm{cm}^{2}\right)$ with scald appearance (up to $30 \%$ of fruits affected) was observed in C-ULO-1.

The content of $\mathrm{CT}_{281}$ in fruits stored under C-RA conditions changed insignificantly with an increase of storage duration, while in C-ULO-2 and C-DCA it significantly increased (up to $20 \mathrm{nmol} / \mathrm{cm}^{2}$ and more), accompanied by the scald appearance after 4.5 months of storage.

After 2 months of storage, 1-MCP treatment provided a strong equivalent inhibition of $\mathrm{CT}_{281}$ accumulation under all studied storage technologies (within 3.2-4.3 nmol/ $\mathrm{cm}^{2}$ ). After 4.5 months of storage, the content of $\mathrm{CT}_{281}$ in T-RA, T-ULO- 2 and T-DCA increased insignificantly and did not exceed $6.1 \mathrm{nmol} / \mathrm{cm}^{2}$, while in T-ULO-1 it increased markedly 
(13.5 $\left.\mathrm{nmol} / \mathrm{cm}^{2}\right)$. During shelf life, $\mathrm{CT}_{281}$ level in T-ULO-1 became comparable with the control one $\left(23.4 \mathrm{nmol} / \mathrm{cm}^{2}\right)$, that ensured the appearance of losses from scald (33\%).

\subsection{Content of $\mathrm{CO} 2, \mathrm{O} 2$, ethylene, $\alpha$-farnesene in the storage atmosphere}

During 4.5 months of storage, $\mathrm{CO}_{2}$ and $\mathrm{O}_{2}$ concentrations in the storage atmosphere corresponded to the declared level for all storage conditions.

After 4.5 months of storage, the ethylene content in the storage atmosphere of control and 1-MCP-treated fruits under RA, ULO-1, ULO-2 and DCA conditions was 1.9, 11, 35 and $12 \mathrm{ppm}$, respectively; the content of $\alpha$-farnesene in indicator tapes reflecting its content in the storage atmosphere was $126,627,78.9$ and $65.1 \mathrm{nmol} / \mathrm{cm}^{2}$, respectively (figure 3), which affected the fruit state.

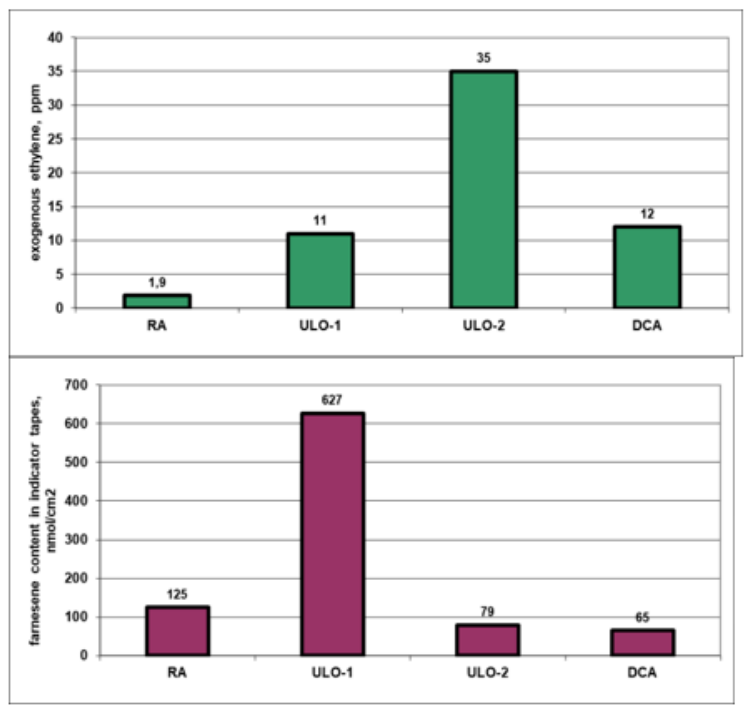

Fig. 3. Ethylene and $\alpha$-farnesene content in the storage atmosphere under RA, ULO-1, ULO-2 and DCA. Data of 2020-2021.

\subsection{Superficial scald and other fruit diseases}

The earliest scald appearance ( 2 months of storage - $10 \%$ of losses) and the highest level of losses from the disease after 4.5 months of storage (95\%) was noted in C-ULO-1 (figure 4). Control fruits stored under RA, DCA and ULO-2 conditions were characterized by later scald appearance (4.5 months of storage) and lower losses from the disease - 5.2, 10 and $27 \%$, respectively, with a decrease in quality (flesh firmness $4.8 \mathrm{~kg} / \mathrm{cm}^{2}$ ), senescent breakdown (2.2\%) and greasiness (up to $60 \%$ ) occurrence under C-RA conditions during shelf life.

The 1-MCP treatment in combination with RA, ULO-2 and DCA storage ensured fruit protection from scald for 4.5 months of storage, with a decrease in quality (flesh firmness $5.4 \mathrm{~kg} / \mathrm{cm}^{2}$ ) and greasiness appearance (up to $10 \%$ ) in T-RA during shelf life. After 4.5 months of storage in T-ULO-1,33\% of the fruits were affected by scald.

Low oxygen storage conditions applied to control and 1-MCP-treated fruits (ULO-1, ULO-2, DCA) for 4.5 months did not cause the development of anaerobic disorders (skin browning, low oxygen breakdown) and the appearance of alcoholic off-flavor in fruits cv. Berkutovskoye. 


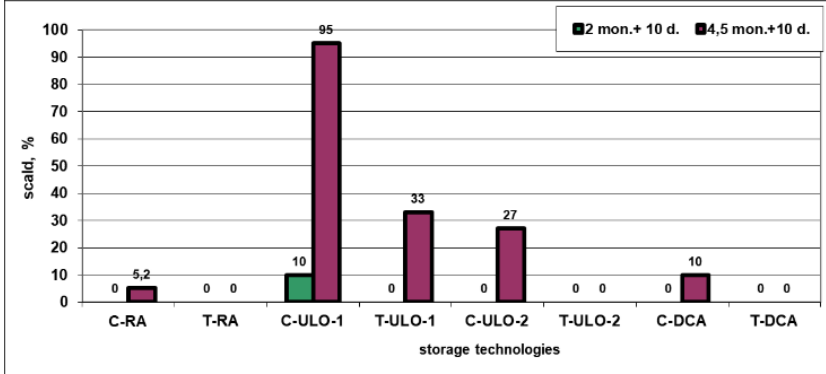

Fig. 4. Effects of storage technologies and storage duration on losses from scald of fruits cv. Berkutovskoye. Data of 2020-2021.

The results of the present research showed that the studied storage conditions without 1MCP applicaton (C-RA, C-ULO-1, C-ULO-2, C-DCA) do not ensure a high level of quality maintenance of fruits $\mathrm{cv}$. Berkutovskoye.

High maturation rates (ethylene accumulation) of fruits stored under C-RA cause a decrease in fruit firmness and appearance of senescent breakdown and greasiness; but it is likely that this factors can contribute to the accumulation of natural antioxidants in fruit skin, which helps to restrain scald development even with a high level of accumulation of the oxidation substrate - $\alpha$-farnesene. The mechanism of protection or reduction of losses from scald is possibly due to partial absorption of low-volatile $\alpha$-farnesene and its oxidation products by fruit skin oils and the antioxidants participation in inhibition the processes of free-radical oxidation of $\alpha$-farnesene, leading to scald development [17]. The effective storage period for fruits under C-RA conditions does not probably exceed 2-3 months.

The limited air exchange under ULO-1, ULO-2 and DCA conditions ensured a different level of quality maintenance of control fruits cv. Berkutovskoye.

The early scald appearance (10\% of losses with mild injuring after 2 months of storage) and $95 \%$ of scalded fruit (severe damage) after 4.5 months of storage in C-ULO-1 are due to the earlier periods of accumulation of $\alpha$-farnesene and its oxidation products $\left(\mathrm{CT}_{281}\right)$ in the cuticle of fruit skin. It is likely that exogenous factors, including the highest level of $\alpha$ farnesene accumulation in indicator tapes $\left(627 \mathrm{nmol} / \mathrm{cm}^{2}\right)$, reflecting its content in the storage atmosphere, had a stimulating effect on scald development [16-17], and the oxygen content within $1.2-1.5 \%$ was insufficient to inhibit the free radical oxidation of $\alpha$-farnesene. The data obtained prove the inexpediency of storing control fruits cv. Berkutovskoye under ULO-1 conditions.

In C-ULO-2 and C-DCA scald appearance was observed after 4.5 months of storage with $27 \%$ and $10 \%$ of losses, respectively, which is significantly lower than in C-ULO-1. Restraining the scald development may be linked with a lower level and later periods of $\mathrm{CT}_{281}$ accumulation in the cuticle of fruit skin, compared with C-ULO-1. This is probably due to the lower oxygen content in the storage atmosphere of C-ULO-2 and C-DCA $(<0.8 \%)$ and lower $\alpha$-farnesene content in indicator tapes $\left(79\right.$ and $65 \mathrm{nmol} / \mathrm{cm}^{2}$, respectively) compared with C-ULO-1. The lower susceptibility to scald under low oxygen storage conditions may be associated with the production of anaerobic metabolites, leading to a delay in the biosynthesis of ethylene and $\alpha$-farnesene as a basis of biological activity for scald development [18].

Probably, the period of effective storage of fruits under C-ULO-2 and C-DCA with the specified storage atmosphere formation regime should be limited to 3-4 months.

There were no differences in biochemical parameters and fruit quality (flesh firmness, appearance of diseases, etc.) between C-ULO-2 and C-DCA, which may be due to differences in the establishing of the storage atmosphere that are insignificant for fruits $\mathrm{cv}$. Berkutovskoe. 
It has been shown that storage technologies for 1-MCP treated fruits (T-RA, T-ULO-1, T-ULO-2, T-DCA) provide a higher level of quality maintenance compared with control fruits.

The 1-MCP treatment ensured effective inhibition of ethylene accumulation (4-6 ppm) and a high level of firmness retention $\left(8.5-9.0 \mathrm{~kg} / \mathrm{cm}^{2}\right)$ under all storage technologies during the first 2 months, under T-ULO-2 and T-DCA - during 4.5 months of storage and shelf life. In T-RA and T-ULO-1 conditions the efficiency of 1-MCP treatment decreased with an increase in storage duration (after 2 months of storage). It should be noted that 1-MCP treatment under all studied storage conditions did not provide a high level of inhibition of the $\alpha$-farnesene synthesis in scald-susceptible fruits cv. Berkutovskoye, which is probably due to the formation of new ethylene binding sites and initiation of ethylene-mediated processes in fruits of cultivars with a high intensity of its synthesis [6].

Obviously, the properties of 1-MCP to reduce or eliminate the losses from scald, as well as the appearance of greasiness on the fruit surface and, probably, a higher level of antioxidant accumulation in fruit skin (as in C-RA), contributed to maintenance of scald sustainability of fruits stored under T-RA, with a decrease in quality, which limits the effective storage period to 3-4 months.

During storage in controlled atmosphere, the fruits stored under T-ULO-1 showed the highest level of $\alpha$-farnesene and $\mathrm{CT}_{281}$ accumulation. Probably, ULO-1 conditions with a high content of $\alpha$-farnesene in the storage atmosphere $\left(627 \mathrm{nmol} / \mathrm{cm}^{2}\right)$ had a stimulating effect on scald development in 1-MCP-treated fruits, while the oxygen content within 1.2$1.5 \%$ was insufficient to inhibit free radical oxidation of $\alpha$-farnesene. The data obtained prove the expediency of limiting the storage period under T-ULO-1 conditions to 3-4 months due to the high risks of scald development.

The inhibition of scald development in fruits stored underT-ULO-2 and T-DCA conditions is due to the lower content of oxygen $(<0.8 \%)$ and $\alpha$-farnesene in the storage atmosphere (79 and $65 \mathrm{nmol} / \mathrm{cm}^{2}$, respectively), compared with fruits stored under ULO-1 or 1-MCP-treated ones. The effective storage period for fruits stored under T-ULO-2 and T-DCA with the specified storage atmosphere formation regime is more than 4.5 months.

It should be noted that after 4.5 months of storage of control and 1-MCP-treated fruits cv. Berkutovskoye under the specific conditions of setup and maintaining of ULO-2 and DCA regimes, there was no development of internal and external disorders and off-flavor appearance that can occur on fruits of other cultivars stored under conditions with low oxygen content $[10,12,18]$.

\section{Conclusion}

The storage efficiency of fruits cv. Berkutovskoe with a high susceptibility to scald and a high intensity of synthesis and production of ethylene, $\alpha$-farnesene and other volatile compounds can be increased by deep inhibition of the postharvest vital activity of fruits with 1-MCP treatment (an inhibitor of ethylene biosynthesis), or without it, while stored under conditions with a low oxygen content $(<0.8 \%)$.

A significant reserve for ripening inhibition and extension of storage duration of fruits $\mathrm{cv}$. Berkutovskoye with the highest quality maintenance is the reduction of the time of establishing storage regime for ULO-2 and the optimization of DCA setup and maintenance algorithm.

A decrease in the oxygen content to $0.8 \%$ in ULO-2 and to $0.4 \%$ in DCA, with and without 1-MCP treatment, did not cause the development of internal and external disorders and an off-flavor appearance in fruits cv. Berkutovskoye, that allows to consider these technologies as promising for the cultivar. Further research is required for their improvement. 


\section{References}

1. K. Apel, H. Hirt, Annu. Rev. Plant Biol., 55, 373 (2004)

2. C. Watkins, W. Bramlage, B. Cregoe, J. Amer. Soc. Hort. Sci., 120, 88 (1995)

3. A. Zanella, Postharvest Biol. Technol., 27, 69 (2003)

4. S. Lurie, C. B. Watkins, Postharvest Biol. Technol., 65, 44 (2012)

5. E. Pesis et al., J. Sci. Food Agric., 90(12), 2114 (2010)

6. S. M. Blankenship, J. M. Dole, Postharvest Biol. Technol., 28(1), 1 (2003)

7. E. Tsantili et al., J. Agric. Food Chem., 55(13), 5267 (2007)

8. C. Moggia et al., Span. J. Agric. Res., 8(1), 178 (2010)

9. R. K. Prange et al., XI International Controlled and Modified Atmosphere Research Conference 1071, 389 (2013)

10. A. Zanella, O. Rossi, Eur. J. Hortic. Sci., 80(1), 11 (2015)

11. A. Mditshwa et al., Scientia Horticulturae, 220, 168 (2017)

12. A.Weber, A. Brackmann, V. Both, E. P. Pavanello, R. d. O. Anese, F. R. Thewes, Scientia Agricola, 72(1), 28 (2015)

13. V. Yu. Rakitin, Plant Physiology, 33, 403 (1986)

14. V. A. Gudkovsky, L. V. Kozhina, RF patent № 2687597/28.04.18, Method of determination of $\alpha$-farnesene and its oxidation products in a storage atmosphere to assess the scald susceptibility of fruits

15. N. P. Morozova, Biochemical Methods, 107 (1980)

16. V. A. Gudkovsky, L. V. Kozhina, Yu. B. Nazarov, Storage and processing of agricultural raw materials, 3, 5 (2016)

17. V. A. Gudkovsky, L. V. Kozhina, Food industry, 12, 58 (2019)

18. R. Sabban-Amin, O. E. Feygenberg, E. Belausov, E. Pesis, Postharvest Biol. Technol., 62(3), 295 (2011) 